Original article

\title{
A SERIAL EVALUATION OF ELECTROCARDIOGRAPHIC INDICES AND CARDIAC ARRHYTHMIAS DURING PREGNANCY, LACTATION AND DRY PERIODS IN SAANEN GOATS
}

\author{
A. S. SAMIMI, J. TAJIK, S. M. AGHAMIRI \& A. KARIMI \\ Department of Clinical Sciences, School of Veterinary Medicine, \\ Shahid Bahonar University of Kerman, Kerman, Iran
}

\section{Summary}

Samimi, A. S., J. Tajik, S. M. Aghamiri \& A. Karimi, 2018. A serial evaluation of electrocardiographic indices and cardiac arrhythmias during pregnancy, lactation and dry periods in Saanen goats. Bulg. J. Vet. Med., 21, No 1, 59-66.

\begin{abstract}
Aim of this study was to investigate the effects of lactation, pregnancy and dry period on electrocardiographic (ECG) parameters and cardiac arrhythmias in the Saanen goat. A total of twenty female adult clinically healthy Saanen goats 3 years of age with a body condition score of 3.5 and average weight of $30.2 \pm 2.20 \mathrm{~kg}$ were randomly selected. The whole duration of the study ( 8 months) was divided into four periods including dry and non-pregnant $\left(\mathrm{P}_{1}\right), 2$ months pregnant $\left(\mathrm{P}_{2}\right), 4$ months pregnant $\left(\mathrm{P}_{3}\right)$, and lactating $\left(\mathrm{P}_{4}\right)$ periods. In late pregnancy and lactation periods, the amplitudes of $\mathrm{P}$, QRS and $T$ waves were significantly higher compared to other periods $(\mathrm{P}<0.01)$. P-R, Q-T and R-R intervals in late pregnancy were significantly shorter and heart rate was significantly higher than those in other periods. Sinus arrhythmias were the only irregularity observed on the ECG traces and were diagnosed in $30 \%, 15 \%, 20 \%$ and $35.25 \%$ of the goats in $\mathrm{P}_{1}, \mathrm{P}_{2}, \mathrm{P}_{3}$ and $\mathrm{P}_{4}$, respectively. There were no significant difference in configuration of ECG waves and cardiac arrhythmias among different periods. Based on the results of the present study, it was concluded that although no cardiac morphological changes have been reported in goats during the lactation, late pregnancy and dry periods, significant changes in ECG parameters were observed in base-apex lead in Saanen goats during late pregnancy and lactation periods. The physiological cardiac arrhythmias and variations in ECG parameters observed during different periods in the current study can be used as a base to achieve more accurate diagnoses of heart diseases using ECG.
\end{abstract}

Key words: cardiac arrhythmias, electrocardiographic indices, dry period, lactation, pregnancy, Saanen goats

\section{INTRODUCTION}

Electrocardiography (ECG) is a noninvasive, practical technique and inexpensive method to determine the disturbances of the cardiac electrical activity (Escudero et al., 2009; Samimi et al., 2015). ECG records have been introduced as an accu- 
rate and very useful tool for evaluation and comparison of cardiac function, diagnosis and classification of cardiac arrhythmias in small ruminants (Cebra \& Cebra, 2012; Escudero et al., 2009). Acidbase disturbances, electrolyte imbalances, variation in discharge of autonomic nervous system and myocardial disease can influence the rate and rhythm of the heart (Radostits et al., 2007). It has been proved that pregnancy and lactation as well as any other stress including pain and excitement affect the cardiovascular system in animals. (Murphy \& Slodzinski, 2008; Pourjafar et al., 2011; Radostits et al., 2007).

Goats, important producers of meat, hair and milk, play a significant socioeconomic role in many countries (Tajik et al., 2013). Saanens, one of the most popular breeds of goat, are raised in large numbers all over the world. They originated in the Saanen valley of Switzerland (Ishag et al., 2012). Saanen goat is probably the most developed dairy breed among other goat breeds (Ellitok, 2012; Ishag et al., 2012; Samimi et al., 2015).

During the pregnancy and lactation periods in sheep, goats and cows, as a result of increased cardiac output following increased heart rate, there's an increase in the blood flow to foetus and mammary tissue (Radostits et al., 2007; Zarifi et al., 2012). In addition to increased heart rate, the increased cardiac size is also involved in supporting cardiac output of cows (Zarifi et al., 2012). There are limited studies investigating the ECG parameters and cardiac arrhythmias in common physiological states such as pregnancy, lactation and non-lactation in small ruminants. Lack of normal reference values and electrocardiographic patterns during lactation, pregnancy and dry period in clinically healthy goats could lead to failure in diagnosis of heart diseases and ab- normal heart rhythm. On the other hand, it has been proven that there are fundamental differences among different breeds of small ruminants for ECG parameters. Although there are some previous studies on ECG parameters in the Saanen goat, to the best of our knowledge, there is no study regarding the effects of different physiological states on ECG indices in this valuable breed. Aim of this study was to investigate the effects of lactation, pregnancy and dry period on ECG parameters and cardiac arrhythmias in the Saanen goat.

\section{MATERIALS AND METHODS}

\section{Animals}

The present study was carried out in a commercial Saanen goat farm around Kerman, southeast of Iran (latitude $30^{\circ} 19^{\prime} \mathrm{N}$ and longitude $52^{\circ} 07^{\prime} \mathrm{E}$ ) during August 2014 to May 2015. A total of twenty female adult clinically healthy Saanen goats 3 years of age with a body condition score of 3.5 and average weight of $30.2 \pm 2.20 \mathrm{~kg}$ were randomly selected. All goats were reared under the same husbandry and management conditions in the same group pen. None of the animals showed clinical signs of heart disease in clinical examination. The animals received anthelmintic treatment at the beginning of the experiment. A constant ration containing a mixture of alfalfa hay $(40 \%)$ and wheat straw (60\%) ad libitum, plus $300 \mathrm{~g}$ of barley grain/head/day, and supplemented with free-choice trace mineral salt licks 3 weeks before breeding. The whole duration of the study ( 8 months) was divided into four periods including dry and non-pregnancy $\left(\mathrm{P}_{1}\right), 2$ months pregnancy $\left(\mathrm{P}_{2}\right), 4$ months pregnancy $\left(\mathrm{P}_{3}\right)$, and lactating $\left(\mathrm{P}_{4}\right)$ periods. Determination of gestational age was determined based on artificial insemination 
date. Pregnancy scanning was done by transcutaneous ultrasonography technique with a $5 \mathrm{MHz}$ linear-array transducer (V8, EMP, China). Single pregnancies were confirmed and ECG recordings were obtained from all goats in the same days.

\section{Procedures}

The ECG was recorded on a bipolar base apex lead using a single channel ECG machine (Cardiomax FX-2111, Fukuda, Japan) with a paper speed of $25 \mathrm{~mm} / \mathrm{s}$ and calibration at $10 \mathrm{~mm} / \mathrm{mV}$. While the animals were kept in a standing position and thought to be in a quiet state (without sedation and minimal restraint), the ECG was recorded using an alligator-type electrode attached to the skin. The positive electrode of lead I (left arm) was placed on the skin of the fifth intercostal space just caudal to the olecranon and the negative electrode (right arm) on the jugular furrow about the lower $1 / 3$ of the left side of the neck. The earth electrode was attached away from these two electrodes (Rezakhani et al., 2004; Tajik et al., 2013). Alligator clips were fixed to the skin after application of methyl alcohol. A magnifying glass was used for analyzing and measuring ECG parameters. The heart rate was calculated by measuring the average six $\mathrm{R}-\mathrm{R}$ intervals of each trace. To describe the QRS complex, the first negative deflection was designated $\mathrm{Q}$, the first positive wave was called $\mathrm{R}$ and the negative deflection after $\mathrm{R}$ was designated $\mathrm{S}$. If the QRS complex was a single negative deflection, it was described as the QS pattern. (DeRoth, 1980; Rezakhani et al,. 2004; Tajik et al., 2013). In the case of biphasic $\mathrm{P}$ or $\mathrm{T}$ waves $(-/+$ or $+/-)$, the amplitude of two phases was summed.

\section{Statistical analysis}

Data were expressed as mean values \pm standard error. Repeated measures ANOVA was used to compare heart rate, wave amplitude and duration, and duration of $\mathrm{P}-\mathrm{R}$, Q-T and R-R intervals among different periods and McNemar's test was implemented for comparison of wave configurations. Statistical analysis was performed using SPSS 17 (SPSS for Windows, version 12, SPSS Inc, Chicago, Illinois). Differences were considered statistically significant when the calculated $\mathrm{P}$ value was less than 0.05 .

Table 1. Electrocardiographic (ECG) indices (in base-apex lead system) in different periods of study in Saanen goats

\begin{tabular}{llcccc}
\hline & $\begin{array}{c}\text { Dry, non- } \\
\text { pregnant }\left(\mathrm{P}_{1}\right)\end{array}$ & $\begin{array}{c}\text { Dry, 2 months } \\
\text { pregnant }\left(\mathrm{P}_{2}\right)\end{array}$ & $\begin{array}{c}\text { Dry, 4 months } \\
\text { pregnant }\left(\mathrm{P}_{3}\right)\end{array}$ & $\begin{array}{c}\text { Lactating, non- } \\
\text { pregnant }\left(\mathrm{P}_{4}\right)\end{array}$ \\
\hline Heart rate $\left(\mathrm{min}^{-1}\right)$ & $115.38 \pm 4.40^{\mathrm{a}}$ & $115.83 \pm 4.90^{\mathrm{a}}$ & $142.85 \pm 4.70^{\mathrm{b}}$ & $93.75 \pm 8.30^{\mathrm{c}}$ \\
\hline Amplitude & $\mathrm{P}$ & $0.155 \pm 0.051^{\mathrm{a}}$ & $0.102 \pm 0.379^{\mathrm{b}}$ & $0.155 \pm 0.51^{\mathrm{c}}$ & $0.105 \pm 0.022^{\mathrm{d}}$ \\
$(\mathrm{mV})$ & $\mathrm{QRS}$ & $0.960 \pm 0.127^{\mathrm{a}}$ & $0.690 \pm 0.129^{\mathrm{b}}$ & $1.350 \pm 0.203^{\mathrm{c}}$ & $1.070 \pm 0.174^{\mathrm{d}}$ \\
& $\mathrm{T}$ & $0.215 \pm 0.067^{\mathrm{a}}$ & $0.265 \pm 0.093^{\mathrm{b}}$ & $0.445 \pm 0.119^{\mathrm{c}}$ & $0.285 \pm 0.093^{\mathrm{d}}$ \\
\hline Duration & $\mathrm{P}$ & $0.040 \pm 0.001$ & $0.042 \pm 0.008$ & $0.042 \pm 0.008$ & $0.040 \pm 0.001$ \\
$(\mathrm{~ms})$ & $\mathrm{QRS}$ & $0.052 \pm 0.018^{\mathrm{a}}$ & $0.040 \pm 0.00^{\mathrm{b}}$ & $0.040 \pm 0.00^{\mathrm{b}}$ & $0.040 \pm 0.00^{\mathrm{b}}$ \\
& $\mathrm{T}$ & $0.054 \pm 0.023^{\mathrm{a}}$ & $0.052 \pm 0.018^{\mathrm{a}}$ & $0.063 \pm 0.021^{\mathrm{a}}$ & $0.074 \pm 0.023^{\mathrm{b}}$ \\
\hline Interval & $\mathrm{P}-\mathrm{R}$ & $0.096 \pm 0.020^{\mathrm{a}}$ & $0.106 \pm 0.019^{\mathrm{a}}$ & $0.087 \pm 0.014^{\mathrm{b}}$ & $0.106 \pm 0.023^{\mathrm{c}}$ \\
$(\mathrm{ms})$ & $\mathrm{Q}-\mathrm{T}$ & $0.238 \pm 0.039^{\mathrm{a}}$ & $0.224 \pm 0.023^{\mathrm{a}}$ & $0.214 \pm 0.019^{\mathrm{a}}$ & $0.286 \pm 0.039^{\mathrm{b}}$ \\
& $\mathrm{R}-\mathrm{R}$ & $0.520 \pm 0.077^{\mathrm{a}}$ & $0.518 \pm 0.049^{\mathrm{a}}$ & $0.420 \pm 0.057^{\mathrm{b}}$ & $0.640 \pm 0.080^{\mathrm{c}}$ \\
\hline
\end{tabular}

Different small superscripts ( $a, b, c$ and d) show significant difference $(\mathrm{P}<0.05)$. 
A serial evaluation of electrocardiographic indices and cardiac arrhythmias during pregnancy ...

Table 2. Comparison of the frequency of electrocardiographic (ECG) waves configuration (in base-apex lead system) in different periods of study in Saanen goats

\begin{tabular}{llcccc}
\hline & & $\begin{array}{c}\text { Dry, non- } \\
\text { pregnant }\left(\mathrm{P}_{1}\right)\end{array}$ & $\begin{array}{c}\text { Dry, 2 months } \\
\text { pregnant }\left(\mathrm{P}_{2}\right)\end{array}$ & $\begin{array}{c}\text { Dry, 4 months } \\
\text { pregnant }\left(\mathrm{P}_{3}\right)\end{array}$ & $\begin{array}{c}\text { Lactating, non- } \\
\text { pregnant }\left(\mathrm{P}_{4}\right)\end{array}$ \\
\hline P wave & + & 16 & 15 & 20 & 18 \\
& +- & 4 & 5 & - & 2 \\
\hline QRS & QS & 8 & 20 & 5 & 5 \\
wave & QRS & 12 & - & 15 & 15 \\
\hline \multirow{2}{*}{ T wave } & + & 16 & 13 & 19 & 2 \\
& $+/-$ & 4 & 7 & 1 & 18 \\
\hline
\end{tabular}

+ , monophasic; +/-, biphasic; QS, presence of 2 deflection in complex; QRS, presence of 3 deflection in complex.

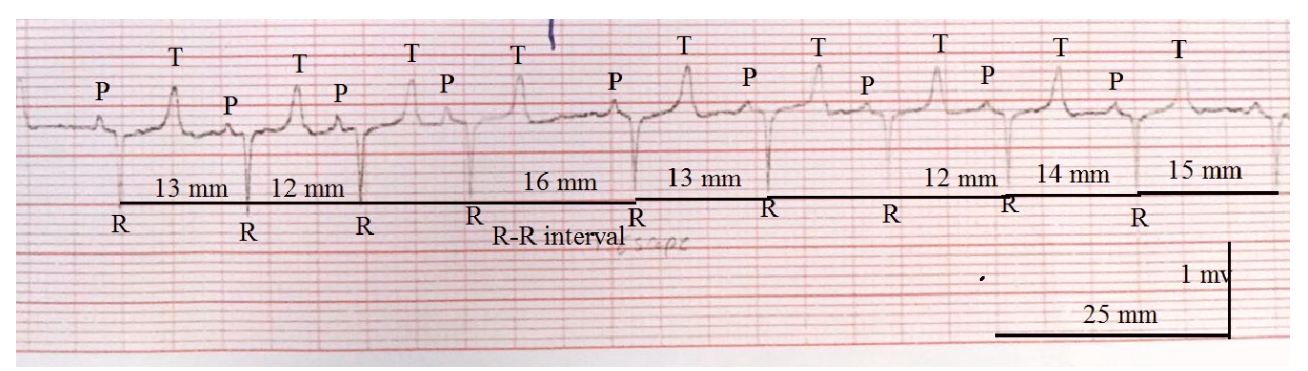

Fig. 1. Electrocardiogram (ECG) tracing from Saanen goats in base-apex lead system (paper speed: $25 \mathrm{~mm} / \mathrm{s}$; calibration: $10 \mathrm{~mm} / \mathrm{mV}$ ). Variable R-R interval during ECG records shows sinus arrhythmia.

\section{RESULTS}

The results of the measurements of the heart rate and amplitude, duration and configuration of ECG waves in different periods are shown in Table 1 and Table 2.

There was a significant difference between dry period and other periods in amplitude of $\mathrm{P}, \mathrm{QRS}$ and $\mathrm{T}$ waves, and also in $\mathrm{QRS}$ duration $(\mathrm{P}<0.01)$. A statistically significant difference was found in heart rate, and $\mathrm{P}-\mathrm{R}, \mathrm{Q}-\mathrm{T}$ and $\mathrm{R}-\mathrm{R}$ intervals among dry period, late pregnancy and lactation period $(\mathrm{P}<0.01)$. In late pregnancy and lactation periods, the amplitudes of P, QRS and T waves were significantly higher compared to other periods
$(\mathrm{P}<0.01)$. P-R, Q-T and R-R intervals in late pregnancy were significantly shorter and heart rate was significantly higher than those in other periods. A biphasic QRS configuration was seen in all periods but early pregnancy in which there was a triphasic pattern, and so there was no possibility of comparison. However, there was no significant difference in configuration of ECG waves among different periods.

Sinus arrhythmias were the only irregularity observed on the ECG traces (Fig. 1) and were diagnosed in 30\%, 15\%, $20 \%$ and $35.25 \%$ of the goats in $\mathrm{P}_{1}, \mathrm{P}_{2}, \mathrm{P}_{3}$ and $\mathrm{P}_{4}$, respectively (Fig. 2). However, no clinical sign of heart problem or cardiac insufficiency was diagnosed in any of the 


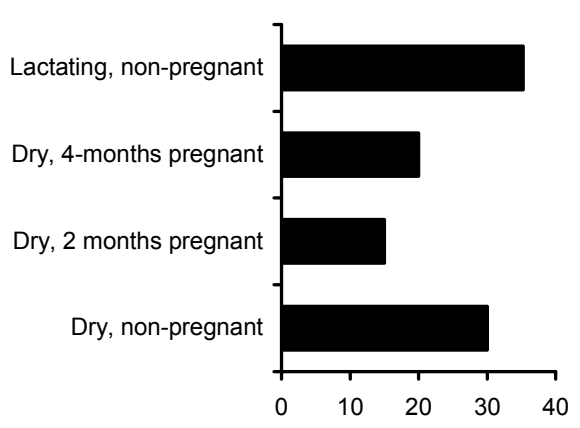

Fig. 2. Frequency (\%) of sinus arrhythmias (in base-apex lead system) in different periods of study in Saanen goats.

cases. Furthermore, there was no significant difference in prevalence of sinus arrhythmias among different periods.

\section{DISCUSSION}

Base apex lead has been proposed as the best and most standard lead for monitoring cardiac electrical activity in large animal medicine and is used routinely (Rezakhani et al., 2004; Radostits et al., 2007; Tajik et al., 2013). To the best of our knowledge, this is the first study on serial evaluation of electrocardiographic indices and cardiac arrhythmias during pregnancy, lactation and dry periods in Saanen goats.

In the studies conducted on adult goats, normal heart rate ranged between $70-110$ beats $/ \mathrm{min}$ and $70-90$ beats $/ \mathrm{min}$, respectively (Radostits et al., 2007; Smith, 2009). However, Pogliani et al. (2013) reported a higher heart rate for adult female Saanen goats (129.42 beats/min) (Pogliani et al., 2013). Our results showed that the mean heart rates in female Saanen goats in $\mathrm{P}_{1}, \mathrm{P}_{2}, \mathrm{P}_{3}$ and $\mathrm{P}_{4}$ were 115.38, $115.83,142.85$ and 93.75 beats/min, respectively (Table 1). Different physiological status such as lactation and pregnancy, conductive properties of the body mass, the volume of the gastrointestinal tract, growth of embryo and increasing size of uterus during pregnancy can influence the distribution of electrical potentials to the body surface (Santamarina et al., 2001) and can be proposed as the cause of different results.

A statistical comparison of $\mathrm{P}, \mathrm{QRS}$ and $\mathrm{T}$ waves amplitude in different periods showed that the amplitude of the waves in lactation and late pregnancy was significantly higher compared to other periods $(\mathrm{P}<0.01)$. It has been reported that cardiac output and total volume of systemic blood flow increased significantly during lactation and late pregnancy compared to dry or early pregnancy periods and these increases may well be associated with increasing milk yields and foetal development, respectively (Davis \& Collier, 1985; Olsson et al., 2001; Pourjafar et al., 2011; Zarifi et al., 2012). Furthermore, lactation and parturition challenge the homeostatic mechanisms of ruminants, especially those controlling the cardiovascular system, and blood flows to the udder and uterus are directly related to milk production and gestational age, respectively (Davis \& Collier, 1985; Olsson et al., 2001; Zarifi et al., 2012). However, it has been documented that the heart size is not influenced by milking and pregnancy status in dairy goats (Olsson et al., 2001). Cardiac output depends on two major factors including heart rate and stroke volume. Stroke volume is influenced by cardiac preload, contractility and after load (Olsson et al., 2001; Radostits et al., 2007). Increase in cardiac contractility to produce an increment in stroke volume and cardiac output results in greater amplitude of ECG waves.

Goats in late pregnancy had significantly higher heart rates and shorter P-R, 
Q-T and R-R intervals compared to goats in other periods. There is a negative correlation between P-R, Q-T and R-R intervals duration and heart rate (Radostits et al., 2007; Jafari-Dehkordi et al., 2012; Pogliani et al., 2013). An increase in heart rate means sinus tachycardia which is initiated by the sinoatrial node. Heart rate increment is caused by some factors such as pain, excitement, stress, pregnancy, exercise, hyperthermia, decrease in arterial blood pressure and administration of adrenergic drugs (Radostits et al., 2007). Stress has been proposed as an important reason for tachycardia (Ville et al., 1993; Bernal \& Moro, 2006;) and our results showed that pregnancy stress was significantly associated with heart rate and higher heart rates were recorded in late pregnancy period compared with other periods $(\mathrm{P}<0.05)$. Increased heart rate in this period may be due to increasing uterus volume, embryonic growth, initiation of colostrum production, high energy demand of embryo, surrounding peritoneal fat, abdominal oedema and increased blood flow to the uterus (Radostits et al., 2007; Zarifi et al., 2012). On the other hand, it is well known that stress increases the plasma corticoid concentrations (Wagner \& Oxenreider, 1972; Meinlschmidt et $a l ., 2010)$ which are regulated by the corticotropin-releasing factor (CRF). CRF is secreted by the hypothalamus in response to stress (Smith \& Dobson, 2002). CRF acts in the central nervous system to stimulate sympathetic noradrenergic outflow to the heart and inhibits cardiac parasympathetic nervous activity, resulting in increased heart rate (Fisher, 1989; Machida et al., 1993; Davis et al., 2002).

The prevalence of sinus arrhythmia was insignificant between different periods. Cardiac dysrhythmias or arrhythmias are defined as disturbances of impulse formation, disorders of impulse conduction, or both (Radostits et al., 2007). Sinus arrhythmia is a normal physiological arrhythmia that occurs at slow resting heart rates and is associated with variation in the heart rate. This arrhythmia has been detected in anorectic cattle (Machida et al., 1991; Gentile et al., 1993), clinically healthy Najdi goats (Pourjafar et al., 2012) and late pregnant sheep (Pourjafar et al., 2011). In the current evaluation, none of the animals with sinus arrhythmia had clinically systemic disease or anorexia but they were under pregnancy and lactation stress. Furthermore, stress is a time of haemodynamic, hormonal, and catecholamine fluctuations, which may provoke cardiac arrhythmias (Murphy \& Slodzinski, 2008). It has been shown that the animals in stress period show sinus arrhythmia more frequently (Rezakhani \& Edjtehadi, 1980). In evaluated animals, this irregular cardiac rhythm could be categorized as physiological arrhythmia. Pourjafar et al. (2012) suggested that the occurrence of sinus tachycardia, sinus arrhythmia and sinoatrial block without clinical manifestations of heart problem in goats is considered as physiological cardiac arrhythmia.

Based on the results of the present study, it was concluded that although no cardiac morphological changes have been reported in goats during the lactation, late pregnancy and dry periods, significant changes in ECG parameters were observed in base-apex lead in Saanen goats during late pregnancy and lactation periods. The physiological cardiac arrhythmias and variations in ECG parameters observed during different periods in the current study can be used as a base to achieve more accurate diagnoses of heart diseases using ECG. 


\section{ACKNOWLEDGEMENTS}

We gratefully acknowledge financial support from the Shahid Bahonar University of Kerman.

\section{REFERENCES}

Bernal, O. \& C. Moro, 2006. Cardiac arrhythmias in women. Revista Española de Cardiología, 59, 609-618.

Cebra, C. \& M. Cebra, 2012. Diseases of the cardiovascular system. In: Sheep and Goat Medicine, $2^{\text {nd }}$ edn, eds D. G. Pugh \& N. N. Baird, pp. 393-396.

Davis, K. L., D. Charney, J. T. Coyle \& C. Nemeroff, 2002. Corticotropin-releasing factor. In: Neuropsychopharmacology: The Fifth Generation of Progress, K. L. Davis, Philadelphia, pp. 95-110.

Davis, S. \& R. Collier, 1985. Mammary blood flow and regulation of substrate supply for milk synthesis. Journal of Dairy Science, 68, 1041-1058.

DeRoth, L., 1980. Electrocardiographic parameters in the normal lactating Holstein cow. The Canadian Veterinary Journal, 21, 271-277.

Ellitok, B., 2012. Reference values for hematological and biochemical parameters in Saanen goats breeding in Afyonkarahisar province. Kocatepe Veterinary Journal, $\mathbf{5}$ 7-11.

Escudero, A., J. R. González, J. L. Benedito, F. R. Prieto \& I. Ayala, 2009. Electrocardiographic parameters in the clinically healthy Zamorano-leones donkey. Research in Veterinary Science, 87, 458-461.

Fisher, L. A., 1989. Corticotropin-releasing factor: Endocrine and autonomic integration of responses to stress. Trends in Pharmacological Sciences, 10, 189-193.

Gentile, A., C. Guglielmini \& M. Cipone, 1993. Alerazioni del ritmo cardiaco nel bovino in rapporto col digiuno. Archivio Veterinario Italiano, 44, 100-107.
Ishag, I., S. Abdalla \& M. Ahmed, 2012. Factors affecting milk production traits of Saanen goat raised under Sudan-semi arid conditions. Online Journal of Animal and Feed Research, 1, 435-438.

Jafari-Dehkordi, A., M. R. Haji-Hajikolaei \& Z. Karimi-Dehkordi, 2012. ECG changes in acute experimental ruminal lactic acidosis in sheep. Veterinary Research Forum, 2, 203-208.

Machida, N., Y. Okamoto, S. Minami, Y. Yamaga \& K. Kagota, 1991. Cardiac arrhythmias in normal Holstein heifers. Journal of the Japan Veterinary Medical Association, 44, 1176-1179.

Machida, N., T. Nakamura, K. Kiryu \& K. Kagota, 1993. Electrocardiographic features and incidence of atrial fibrillation in apparently healthy dairy cows. Journal of Veterinary Medicine Series A, 40, 233239.

Meinlschmidt, G., C. Martin, I. D. Neumann $\&$ M. Heinrichs, 2010. Maternal cortisol in late pregnancy and hypothalamic-pituitaryadrenal reactivity to psychosocial stress postpartum in women. Stress, 13, 163-171.

Murphy, J. \& M. Slodzinski, 2008. Right ventricular outflow tract tachycardia in the parturient. International Journal of Obstetric anesthesia, 17, 275-278.

Olsson, K., K. Hansson, E. Hydbring, L. Walter \& J. Häggström, 2001. A serial study of heart function during pregnancy, lactation and the dry period in dairy goats using echocardiography. Experimental Physiology, 86, 93-99.

Pogliani, F. C., E. H. Birgel Junior, B. M. Monteiro, J. H. Grisi Filho \& R. F. Raimondo, 2013. The normal electrocardiogram in the clinically healthy Saanen goats. Pesquisa Veterinária Brasileira, 33, 1478-1482.

Pourjafar, M., K. Badiei, A. Chalmeh, A. Sanati, A. Shahbazi, M. Badkobeh \& M. Bagheri, 2012. Age-related cardiac arrhythmias in clinically healthy Iranian Najdi goats. Bulgarian Journal of Veterinary Medicine, 15, 37-43. 
A serial evaluation of electrocardiographic indices and cardiac arrhythmias during pregnancy...

Pourjafar, M., K. Badiei, A. A. Chalmeh, A. R. Sanati \& H. Sabouri, 2011. Comparison of cardiac arrhythmias between late pregnancy and early post-partum periods in clinically healthy Iranian fat-tailed sheep. Pakistan Veterinary Journal, 31, 309-312.

Radostits O. M., C. Gay, K. W. Hinchcliff \& P. D. Constable, 2007. Diseases of the cardiovascular system. In: Veterinary $\mathrm{Me}$ dicine: A Textbook of the Diseases of Cattle, Horses, Sheep, Pigs and Goats, London, pp. 399-438.

Rezakhani, A. \& M. Edjtehadi, 1980. Some electrocardiographic parameters of the fattailed sheep. Zentralblatt für Veterinärmedizin Reihe A, 27, 152-156.

Rezakhani, A., A. A. Paphan \& S. Shekarfroush, 2004. Analysis of base apex lead electrocardiograms of normal dairy cows. Veterinarski arhiv, 74, 351-358.

Samimi, A., S. M. Aghamiri, J. Tajik, T. Taheri \& R. Eshteraki, 2015. Analysis of cardiac arrhythmias and electrocardiographic indices of clinically healthy Saanen goats in different sexes and age groups. Eurasian Journal of Veterinary Sciences, 31, 192-196.

Santamarina, G., L. Espino \& M. L. Suarez, 2001. Electrocardiographic parameters of free-ranging roe deer (Capreolus capreolus). Journal of Zoo and Wildlife Medicine, 32, 441-446.

Smith, B. P., 2009. Large Animal Internal Medicine, $4^{\text {th }}$ edn, Mosby Elsevier, St. Louis.

Smith, R. \& H. Dobson, 2002. Hormonal interactions within the hypothalamus and pituitary with respect to stress and reproduction in sheep. Domestic Animal Endocrinology, 23, 75-85.

Tajik, J., A. Samimi, T. Tajik, S. Bakhshaei \& A. Mirjordavi, 2013. Electrocardiographic parameters in clinically healthy Cashmere goats. Online Journal of Veterinary Research, 17, 528-534.

Ville, H., S. Bertels, R. Geers, S. Janssens, V. Goedseels, G. Parduyns, J. Van Bael, K. Goossens, L. Bosschaerts \& J. De Ley, 1993. Electrocardiogram parameters of piglets during housing, handling and transport. Animal Production, 56, 211216.

Wagner, W. \& S. Oxenreider, 1972. Adrenal function in the cow. Diurnal changes and the effects of lactation and neurohypophyseal hormones. Journal of Animal Science, 34, 630-635.

Zarifi, M., S. Buczinski, A. Rezakhani, M. R. M. Dezfouli \& A. Khonsha, 2012. Effect of lactation on functional and morphological echocardiographic variables in adult dairy cows. Journal of Veterinary Cardiology, 14, 415-421.

Paper received 19.02.2016; accepted for publication 10.06.2016

\section{Correspondence:}

Amir Saeed Samimi, DVM, DVSc Department of Clinical Sciences, School of Veterinary Medicine, Shahid Bahonar University of Kerman, 7616914111Kerman, Iran, tel.: +983413202935 ,

fax: +983413222047 email: amirsamimi90@yahoo.com 